\title{
Bendamustine/Brentuximab Vedotin Regimen
}

National Cancer Institute

\section{Source}

National Cancer Institute. Bendamustine/Brentuximab Vedotin Regimen. NCI Thesaurus. Code C160524.

A reg imen consisting of bendamustine and brentuximab vedotin that can be used for the treatment of relapsed or refractory Hodgkin lymphoma $(\mathrm{HL})$. 